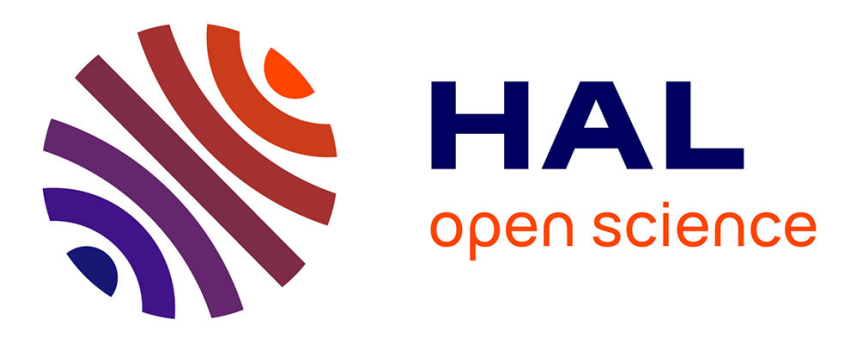

\title{
Extensible Beam Models in Large Deformation Under Distributed Loading: a Numerical Study on Multiplicity of Solutions
}

Francesco Dell'Isola, Alessandro Della Corte, Antonio Battista, Emilio Barchiesi

\section{To cite this version:}

Francesco Dell'Isola, Alessandro Della Corte, Antonio Battista, Emilio Barchiesi. Extensible Beam Models in Large Deformation Under Distributed Loading: a Numerical Study on Multiplicity of Solutions. Holm Altenbach Wolfgang H. Müller Bilen Emek Abali. Higher Gradient Materials and Related Generalized Continua, 120, Springer, pp.19-41, 2019, Advanced Structured Materials, 10.1007/978-3030-30406-5 . hal-02475674

\section{HAL Id: hal-02475674 https://hal.science/hal-02475674}

Submitted on 25 Aug 2020

HAL is a multi-disciplinary open access archive for the deposit and dissemination of scientific research documents, whether they are published or not. The documents may come from teaching and research institutions in France or abroad, or from public or private research centers.
L'archive ouverte pluridisciplinaire HAL, est destinée au dépôt et à la diffusion de documents scientifiques de niveau recherche, publiés ou non, émanant des établissements d'enseignement et de recherche français ou étrangers, des laboratoires publics ou privés. 


\title{
Extensible Beam Models in Large Deformation Under Distributed Loading: a Numerical Study on Multiplicity of Solutions
}

\author{
Francesco dell'Isola, Alessandro Della Corte, Antonio Battista, and Emilio \\ Barchiesi
}

\begin{abstract}
In this paper we present numerical solutions to a geometrically nonlinear version of the extensible Timoshenko beam model under distributed load. The particular cases in which: i) extensional stiffness is infinite (inextensible Timoshenko model), ii) shear stiffness is infinite (extensible Euler model) and iii) extensional and shear stiffnesses are infinite (inextensible Euler model) will be numerically explored. Parametric studies on the axial stiffness in both the Euler and Timoshenko cases will also be shown and discussed.
\end{abstract}

\footnotetext{
F. dell'Isola

International Research Center for the Mathematics and Mechanics of Complex Systems M\&MoCS, Università dell' Aquila, L'Aquila

Department of Structural and Geotechnical Engineering, Università di Roma La Sapienza, 18 Via Eudossiana, Rome, Italy

Research Institute for Mechanics, Nizhny Novgorod Lobachevsky State University, 23, Gagarin av. 603950 Nizhny Novgorod, Russia

e-mail: francesco.dellisola.me@gmail.com
A. Della Corte
International Research Center for the Mathematics and Mechanics of Complex Systems - M\&MoCS, Università dell'Aquila, L'Aquila
Department of Structural and Geotechnical Engineering, Università di Roma La Sapienza, 18 Via Eudossiana, Rome, Italy
e-mail: alessandro.dellacorte.memocs@gmail.com

\author{
A. Battista \\ International Research Center for the Mathematics and Mechanics of Complex Systems - \\ M\&MoCS, Università dell'Aquila, L'Aquila, Italy \\ LaSIE, Université de La Rochelle, La Rochelle, France \\ e-mail: antonio.battista@uni-lr.fr \\ E. Barchiesi \\ International Research Center for the Mathematics and Mechanics of Complex Systems - \\ M\&MoCS, Università dell' Aquila, L'Aquila \\ Department of Structural and Geotechnical Engineering, Università di Roma La Sapienza, 18 Via \\ Eudossiana, Rome, Italy \\ e-mail: barchiesiemilio@gmail.com
}


Keywords: Timoshenko beam - Large deformation of beams - Extensional beam model $\cdot$ Shooting technique

\subsection{Introduction}

In the recent literature the behaviour of a clamped-free nolinear inextensible Euler Elastica introduced in Euler (1952); Bernoulli (1843, 1691); see Luongo and Zulli (2013); Eugster (2015); Steigmann and Faulkner (1993) for general reference works, has been mathematically investigated under distributed load (Della Corte et al, 2016). In particular, the set of stable equilibrium configurations has been completely characterized in Della Corte et al (2019). On the other hand, extending such rigorous results to the extensible Euler beam model, or to the Timoshenko beam model is not straightforward. Indeed, the presence of the additional kinematical descriptor accounting for extensibility gives rise to various new mathematical difficulties. The most basic one is that it changes the functional set in which the problem is naturally collocated and in particular prevents it from being a vector space, since a strictly positive local axial deformation has to be prescribed. Of course one can obtain this making suitable assumptions on the energy, but in any case the nonautonomous variational problem that arises in the case of a distributed load will present new difficulties with respect to the inextensible case (Battista et al, 2018).

The problem of existence and stability of equilibrium configurations for extensible Euler and Timoshenko beams in large deformations under distributed load is therefore an open one. Because of this reason, it is interesting to study the behavior of solutions by means of a systematic collection of parametric studies starting from the inextensible Elastica and approaching more general beam models. The present work is aimed at performing such kind of investigation. Our main effort will be to show the variety of different (and at times rather exotic) equilibrium configurations that can arise when the value of the load is large enough. Moreover, we want to numerically investigate how fast the number of possible equilibrium solutions increases with the load and how this particular feature is affected by allowing shear deformation.

The study of these exotic configurations is particularly important, nowadays, due to the enhancement of computational methods that make nonlinearity more practically relevant for structural members (Fertis, 2006; Ladevèze, 2012; Antman and Renardy, 1995; Rezaei et al, 2012; Eugster et al, 2014; Steigmann, 2017) as well as in machine mechanics applications (Pepe et al, 2016; Giorgio and Del Vescovo, 2018). Moreover, they are becoming fashionable as an elementary constituent of microstructured objects manufactured with computer-aided techniques (Atai and Steigmann, 1997; dell'Isola et al, 2016b; Ravari and Kadkhodaei, 2015; Ravari et al, 2014; dell'Isola et al, 2016a; Turco et al, 2016, 2017; Milton et al, 2017; Spagnuolo et al, 2017). These objects are potentially advantageous for their mechanical characteristics, as shown in recent literature (Boutin et al, 2017; Giorgio et al, 2017; Scerrato et al, 2016; Eremeyev, 2017; Golaszewski et al, 2019; Turco et al, 2019; 
Franciosi et al, 2019) and their theoretical study requires tools from homogenization theory (Boubaker et al, 2007; Ravari et al, 2016; Dos Reis and Ganghoffer, 2012; Reda et al, 2016), discrete mechanics (Turco, 2018; Jawed et al, 2018; Andreaus et al, 2018), theory of generalized continua (Misra et al, 2016; Altenbach et al, 2013; Altenbach and Eremeyev, 2013; Placidi et al, 2017, 2014, 2016) as well as developments in nonlinear elasticity of beams. In this last regard, certainly a full understanding of the onset and the characteristics of multiple solutions for the static problem under distributed load would be an important step forward, and possibly more general beam models will also have to be considered (Diyaroglu et al, 2015; Challamel, 2013; Challamel et al, 2013) because of the exotic properties of microstructured continua (Misra et al, 2018; dell'Isola et al, 2018; Diyaroglu et al, 2017).

The paper is organized as follows: we introduce the general model for a nonlinear version of the Timoshenko beam; we deduce the equilibrium equations by means of the Lagrange multipliers method. Then, imposing stationarity to the energy functional, we deduce an expression for the total energy in stationary points which depends only on the angles formed by the tangent to the deformed shape. Then we show and discuss numerical results on the multiplicity of solutions with large value of the load and on the effect of releasing extensional stiffness in both the Euler and the Timoshenko case. Finally we propose some future research directions.

\subsection{The Model}

\subsubsection{Kinematics and Deformation Energy}

Let $\left\{\boldsymbol{D}_{1}, \boldsymbol{D}_{2}\right\}$ be an orthogonal reference system in which the beam lies in the unstressed configuration along $\boldsymbol{D}_{1}$. We will denote by $s$ the abscissa along the beam, by the apex ' the differentiation with respect to the reference abscissa ${ }^{1}$ and by $\chi(s)$ the placement function. The tangent vector to the current configuration of the beam is then:

$$
\boldsymbol{\chi}^{\prime}=\alpha(s)\left[\cos (\theta(s)) \boldsymbol{D}_{\mathbf{1}}+\sin (\theta(s)) \boldsymbol{D}_{\mathbf{2}}\right]:=\alpha(s) \boldsymbol{e}(\theta(s))
$$

where $e(\theta(s))$ represents the unit vector parallel to $\chi^{\prime}$. Therefore $\alpha(s)$ describes the local elongation of the beam:

$$
\left\|\chi^{\prime}(s)\right\|=\alpha(s)
$$

while $\theta(s)$ is the angle between $\chi^{\prime}(s)$ and $\boldsymbol{D}_{\mathbf{1}}$.

We will assume the following energy functional:

\footnotetext{
${ }^{1}$ Notice that this means that, denoting by $\theta$ the angle formed by the tangent to the deformed shape and a reference axis, $\theta^{\prime}$ does not coincide with the geometrical curvature but with the so-called Chebyshev curvature (see Chebyshev, 1878).
} 


$$
\mathcal{E}^{\text {def }}(\chi, \varphi):=\int_{0}^{L}\{\underbrace{\frac{k_{e}}{2}\left(\left\|\chi^{\prime}(s)\right\|-1\right)^{2}}_{\text {extensional energy }}+\underbrace{\frac{k_{b}}{2}\left(\varphi^{\prime}(s)\right)^{2}}_{\text {flexural energy }}+\underbrace{\frac{k_{t}}{2}(\varphi(s)-\theta(s))^{2}}_{\text {shear energy }}\} d s
$$

Here $\varphi$ is the angle between sections of the beam (supposed rigid) and the normal to the neutral axes, while $k_{b}, k_{e}$ and $k_{t}$ are respectively the bending, extensional and shear stiffness. The energy can be rewritten as:

$$
\varepsilon^{\text {def }}=\int_{0}^{L}\left\{\frac{k_{e}}{2}(\alpha-1)^{2}+\frac{k_{b}}{2}\left(\varphi^{\prime}(s)\right)^{2}+\frac{k_{t}}{2}(\varphi(s)-\theta(s))^{2}\right\} d s .
$$

We introduce now a uniformly distributed load $\boldsymbol{b}(s)$ and a concentrated load and couple in the endpoint of the beam $s=L$, denoted respectively by $\boldsymbol{R}(L)$ and $M(L)$. The total energy of the system is then:

$$
\begin{aligned}
\mathcal{E}^{\mathrm{tot}}= & \int_{0}^{L}\left\{\frac{k_{e}}{2}(\alpha-1)^{2}+\frac{k_{b}}{2}\left(\varphi^{\prime}(s)\right)^{2}+\frac{k_{t}}{2}(\varphi(s)-\theta(s))^{2}-\boldsymbol{b} \cdot \boldsymbol{\chi}\right\} d s \\
& -\boldsymbol{R} \cdot \boldsymbol{\chi}(L)-\boldsymbol{M} \varphi(L)
\end{aligned}
$$

The beam model described by the functional (2.5) is a geometrically nonlinear version of the Timoshenko beam model (introduced in Timoshenko, 1921, 1922), which is a particular case of Cosserat continuum introduced in Cosserat and Cosserat (1909); for general references and interesting results see e.g. Altenbach et al (2010); Birsan et al (2012); Forest (2005); Eremeyev and Pietraszkiewicz (2016)). Interesting generalizations of the Timoshenko beam model have been proposed (see e.g. Romano et al, 1992; Serpieri and Rosati, 2014), while a periodic mechanical system whose homogenized limit is the model (2.5) (in the particular case $\alpha \equiv 1$ ) is shown in Battista et al (2018). It is in fact a microstructured 1D system whose unit cell is an articulated parallelogram and equipped with suitably placed rotational springs, and it can be easily obtained by means of 3D printing. Of course also other (possibly more complex) microstructured systems can have a similar homogenized version (on microstructured continua see e.g. Barchiesi et al, 2019; Engelbrecht and Berezovski, 2015; Engelbrecht et al, 2005; Barchiesi et al, 2018).

\subsubsection{Lagrange Multipliers Method}

Given the total energy of the system, equilibrium configurations are found as stationary points of the energy functional (2.5). A synthetic formulation of the problem, taking into account together the constrain of Eq. (2.1) and the total energy, is obtained with the introduction of a Lagrange multiplier $\boldsymbol{\Lambda}(s)$. We get the following functional formulation: 


$$
\begin{aligned}
\mathcal{E}^{\mathrm{tot}} & =\int_{0}^{L}\left\{\frac{k_{e}}{2}(\alpha-1)^{2}+\frac{k_{b}}{2}\left(\varphi^{\prime}(s)\right)^{2}+\frac{k_{t}}{2}(\varphi(s)-\theta(s))^{2}-\boldsymbol{b} \cdot \boldsymbol{\chi}+\right. \\
& \left.+\boldsymbol{\Lambda} \cdot\left(\chi^{\prime}-\alpha\left[\cos (\theta(s)) \boldsymbol{D}_{\mathbf{1}}+\sin (\theta(s)) \boldsymbol{D}_{\mathbf{2}}\right]\right)\right\} d s-\boldsymbol{R} \cdot \boldsymbol{\chi}(L)-\boldsymbol{M} \varphi(L)
\end{aligned}
$$

i.e., the energy is a function of the fields $\alpha(s), \varphi(s), \theta(s), \boldsymbol{\chi}(s), \boldsymbol{\Lambda}(s)$. The first variation of the energy with respect to these fields (considered independent) gives the two boundary value problems (BVPs):

$$
\left\{\begin{array}{l}
-k_{b} \varphi^{\prime \prime}+k_{t}(\varphi-\theta)=0 \\
k_{b} \varphi^{\prime}(L) \delta \varphi(L)=M \delta \varphi(L) \\
k_{b} \varphi^{\prime}(0) \delta \varphi(0)=0
\end{array}\right.
$$

and

$$
\left\{\begin{array}{l}
-\boldsymbol{\Lambda}^{\prime}-\boldsymbol{b}=0 \\
\boldsymbol{\Lambda}(L) \cdot \delta \boldsymbol{\chi}(L)=\boldsymbol{R} \cdot \boldsymbol{\delta} \chi(L) \\
\boldsymbol{\Lambda}(0) \cdot \delta \boldsymbol{\chi}(0)=0
\end{array}\right.
$$

as well as the algebraic relations:

$$
\begin{array}{r}
k_{t}(\varphi-\theta)+\alpha \boldsymbol{\Lambda} \cdot \boldsymbol{e}_{\perp}(\theta)=0 \\
k_{e}(\alpha-1)-\boldsymbol{\Lambda} \cdot \boldsymbol{e}(\theta)=0
\end{array}
$$

and the kinematic constraint Eq. (2.1).

In Eq. (2.9) we introduced:

$$
\boldsymbol{e}_{\perp}(\theta(s))=-\sin (\theta(s)) \boldsymbol{D}_{1}+\cos (\theta(s)) \boldsymbol{D}_{2}
$$

and the two boundary conditions in 0 are imposed considering a cantilever beam (lying along $\boldsymbol{D}_{1}$ in the reference configuration and clamped in the extreme $s=0$ ).

\subsection{Numerical Simulations}

\subsubsection{Numerical Methods}

An increasingly popular approach for the numerical study of nonlinear beams is isogeometric analysis (see e.g. Balobanov and Niiranen, 2018; Niiranen et al, 2017; Cazzani et al, 2016; Greco et al, 2017; Dortdivanlioglu et al, 2017), which is a 
suitable variant of the finite element method. This method is very powerful and relatively light from a computational point of view, but just like every energy-related method it is not very suitable to study the multiplicity of arising solutions. For this reason, the numerical technique used here is the same as in Battista et al (2018). Indeed, the boundary value problem for the clamped-free Euler and Timoshenko beams has been solved by means of a shooting technique. We introduce a family of Cauchy problems ${ }^{2}$ :

$$
\mathcal{P}_{k}=\left\{\begin{array}{l}
\theta^{\prime \prime}=-b(1-s) \cos \theta \\
\theta(0)=0 \\
\theta^{\prime}(0)=k
\end{array}\right.
$$

depending on the parameter $k$. Then we selected the solutions of (2.11) which satisfy (with prescribed accuracy) $\theta^{\prime}(1)=0$, so as to obtain a numerical solution of the equilibrium condition $\delta \mathcal{E}^{t o t}=0$. Clearly the solution for the Cauchy problem exists and is unique for every initial datum $k$.

In Fig. 2.1, we show the plot of $\theta^{\prime}(1)$ as a function of $k:=\theta^{\prime}(0)$ for an inextensible Euler beam model for $b=250$. The graph intersects in five different points the horizontal axis, which means that in this case we have five different solutions of the boundary value problem with $\theta(0)=0$ and $\theta^{\prime}(1)=0$. In the next section, the solutions will be shown in the same order as they appear as intersections between $\theta^{\prime}(1)$ and the horizontal axis. Therefore the absolute minimum of the total energy will be always the rightmost configuration and, of course, the only solution for $b$ small enough.

Fig. 2.1 $\theta^{\prime}(1)$ as a function of $k:=\theta^{\prime}(0)$ for an inextensible Euler beam with a transverse applied load $b=250$. Solutions to the boundary value problem (2.11) correspond to the intersections of the curve with the horizontal axis.

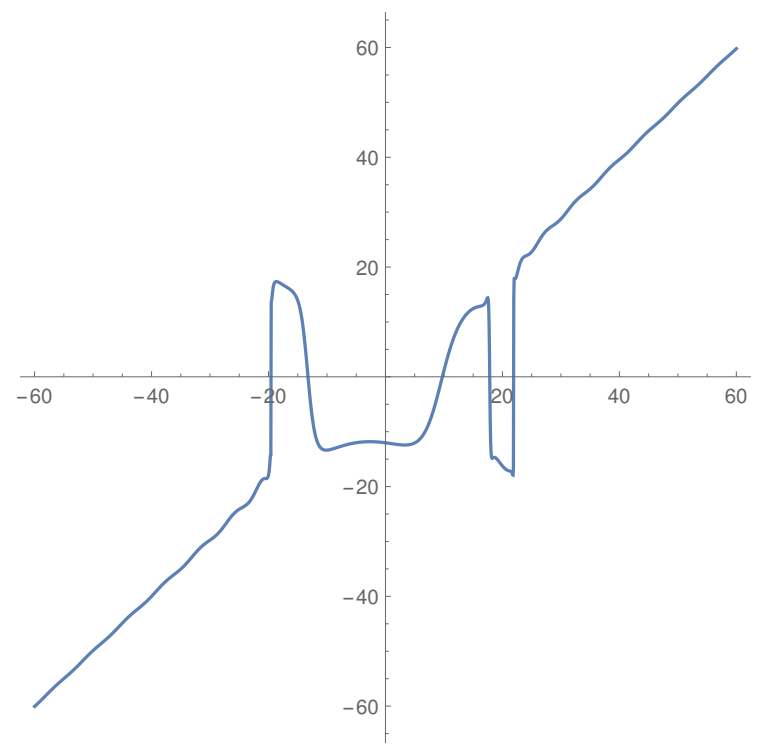

${ }^{2}$ We consider here the inextensible Euler beam for simplicity, but everything is analogous for the general case. 
Remark 2.1. Of course this numerical technique can only capture regular equilibrium configurations. It is well-known that the minima (and maxima) of nonautonomous functionals may be not regular enough to satisfy the Euler-Lagrange equations (even in the one-dimensional case as in Ball and Mizel, 1987). This, together with the assessment of the stability of the solutions, is the main reason for which a rigorous study of the problem will be crucial.

\subsubsection{The Number of Equilibrium Configurations when the Load Increases}

It is generally very difficult to address theoretically the problem of evaluating how fast the number of solutions of a nonlinear parametric dynamical system increases with the parameter (Guckenheimer and Holmes, 1983), which in our case is the external load. It is therefore interesting, as a preliminary step, to address the problem numerically. In Fig. 2.2 the number of solutions for an inextensible (left) and extensible (right) Euler beem model is plotted as a function of the non-dimensional external load. As expected, the behavior is that of a step-function, as it is clear that new branches of solutions arise only when the external load overcomes specific thresholds. The number of equilibrium configurations increases significantly with the load, and again as expected it reaches slightly larger values in case an additional kinematic degree of freedom (i.e. $\alpha$ ) is included.

Figure 2.3 is consistent with this. Indeed, in this case inextensible (left) and extensible (right) Timoshenko beam models are considered, which produces an even more rapid increase of the possible equilibrium configurations. It has to be remarked, however, that a straight comparison with the Euler case is difficult because adimensionalizing the load is a different procedure in the two cases.
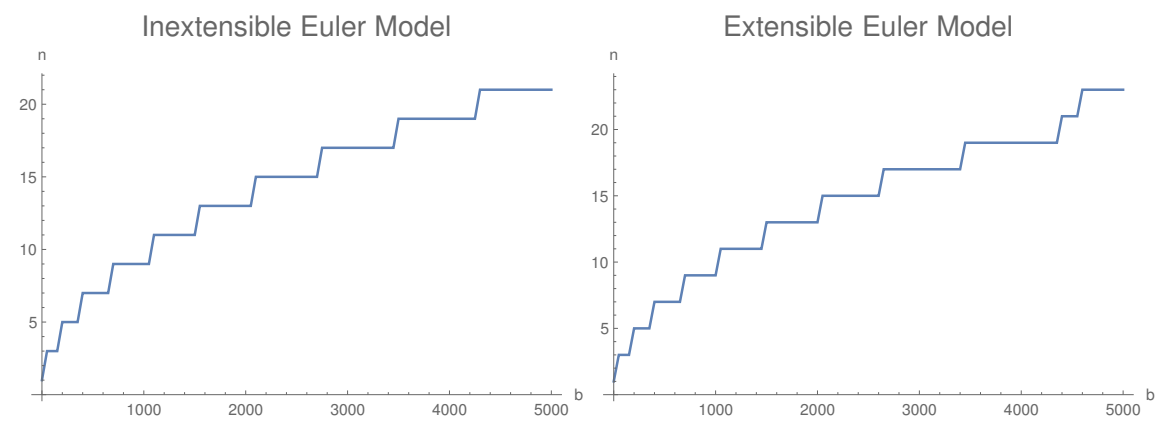

Fig. 2.2 Number of solutions, $n$, as a function of the transversal applied load, $b$. Left: inextensible Euler model. Right: extensible Euler model $\left(k_{e}=1.3 \times 10^{3}\right)$. 

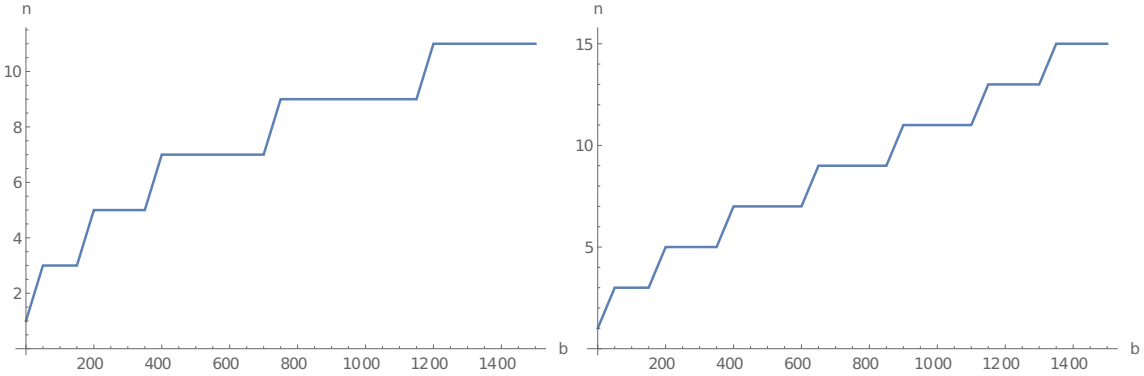

Fig. 2.3 Number of solutions, $n$, as a function of the transversal applied load, $b$. Left: inextensible Timoshenko model $\left(k_{t}=1.8 \times 10^{4}\right)$. Right: extensible Timoshenko model $\left(k_{t}=1.8 \times 10^{4}\right.$, $\left.k_{e}=2 \times 10^{3}\right)$.

\subsubsection{Equilibrium Configurations}

In the first gallery of equilibrium solutions we will show the full set of equilibrium configurations when the nondimensional load is $b=60, b=250$ and $b=500$. We considered inextensible Euler (Figs. 2.4, 2.8, 2.12), extensible Euler (Figs. 2.5, 2.9, 2.13), inextensible Timoshenko (Figs. 2.6, 2.10, 2.14) and extensible Timoshenko (Figs. 2.7, 2.11, 2.15) beam models.

For the chosen values of the other parameters, we have the same number of solutions (when applying the same load) for the four beam models. It has to be remarked that no branch of solutions appear to bifurcate. Instead, when the load increases, new branches appear at some thresholds. It can be seen that $\theta(s)$ is a positive monotonic function for the rightmost solution in all the cases. For $b=60$ the central equilib-
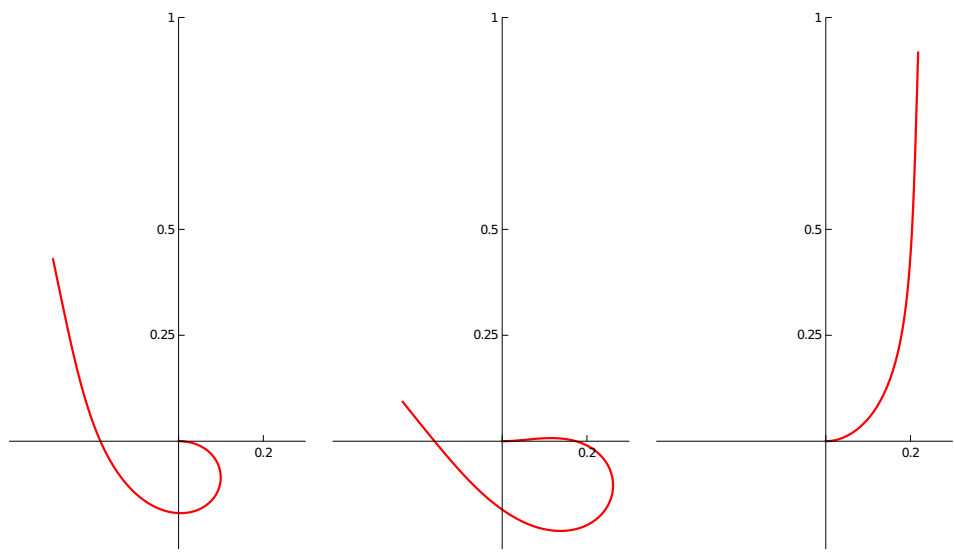

Fig. 2.4 Clamped inextensible Euler beam with a transversal applied load $b=60$ 

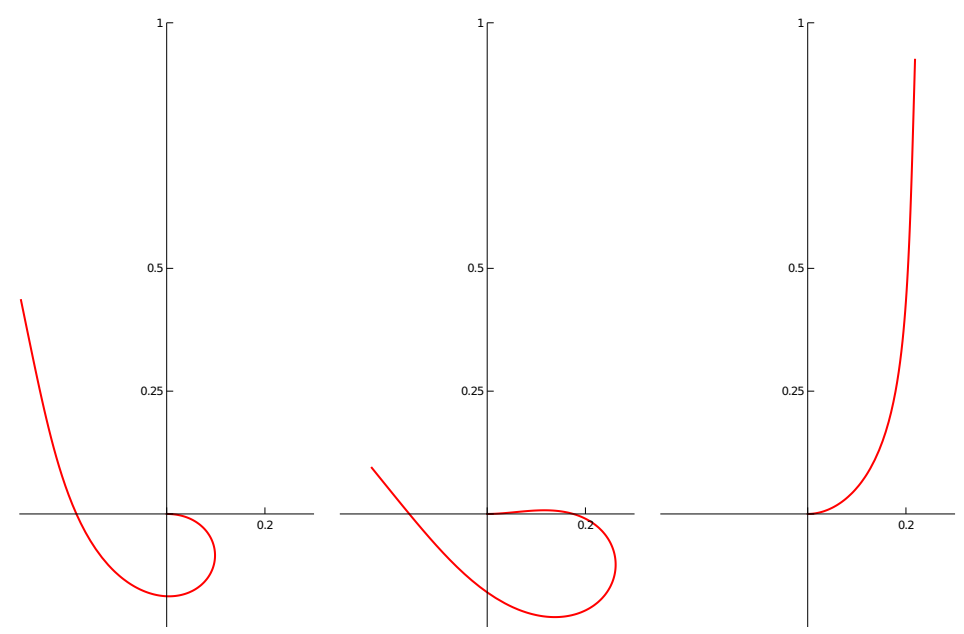

Fig. 2.5 Clamped extensible Euler beam with a transversal applied load $b=60\left(k_{e}=3000\right)$
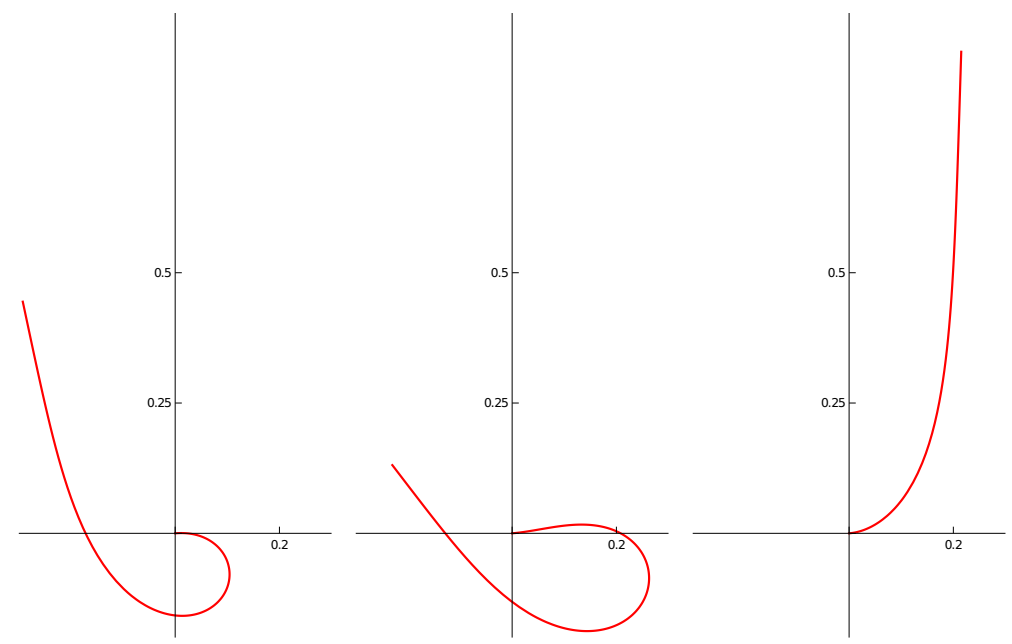

Fig. 2.6 Clamped inextensible Timoshenko beam with a transversal applied load $b=60$ $\left(k_{t}=7000\right)$

rium shape is non monotonic, while the leftmost is a negative monotonic function. This is a general trend as the load increases. Indeed, branches that arise with increasingly large values of the load will be made of progressively more numerous monotonic pieces. Of course in the Timoshenko case in general it is $\theta(0) \neq 0$. As the boundary datum for $\theta$ in 0 can have more than one solution, we have always chosen the smallest one in absolute value (see also the Appendix). The axial elongation relative to Figs. 2.9 and 2.11 are shown respectively in Figs. 2.16 and 2.18. The shear 

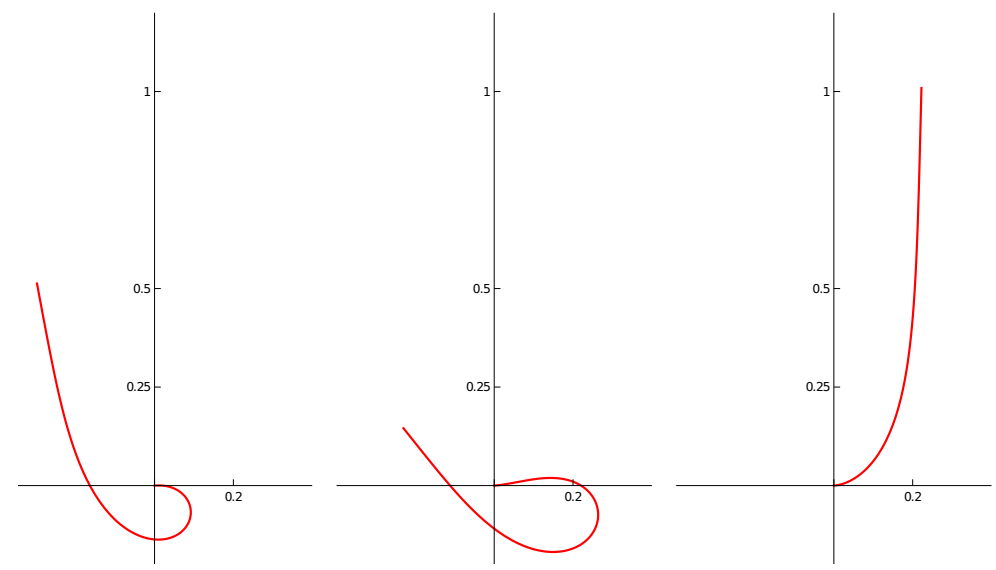

Fig. 2.7 Clamped extensible Timoshenko beam with a transverse applied load $b=60\left(k_{t}=7000\right.$, $\left.k_{e}=3000\right)$
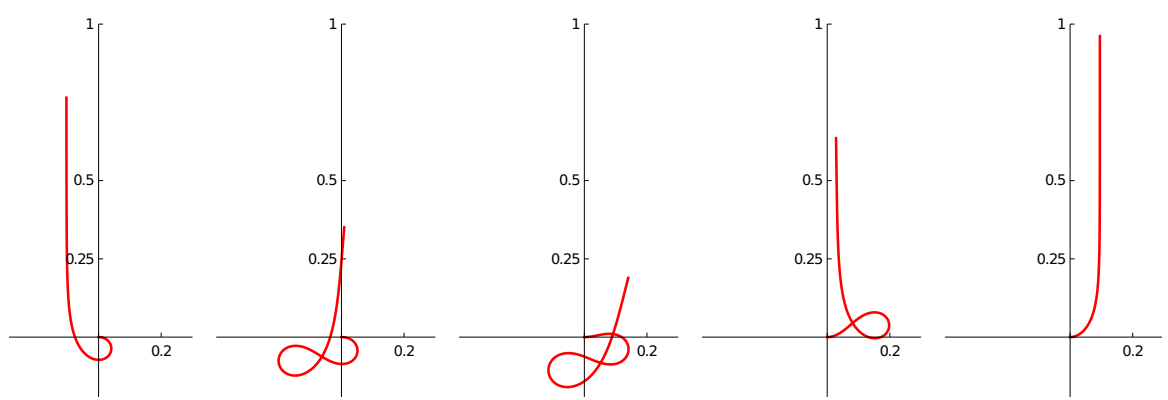

Fig. 2.8 Clamped inextensible Euler beam with a transversal applied load $b=250$
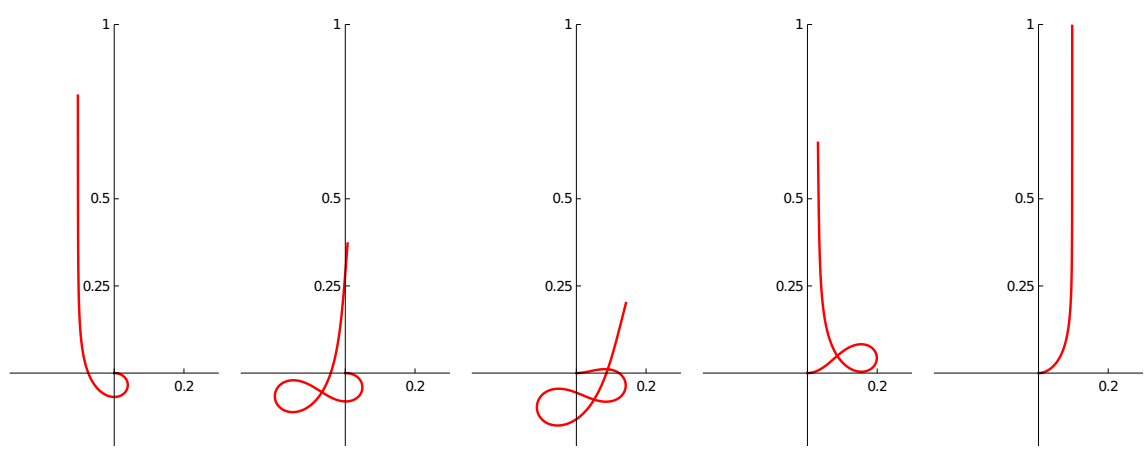

Fig. 2.9 Clamped extensible Euler beam with a transversal applied load $b=250\left(k_{e}=3000\right)$ 

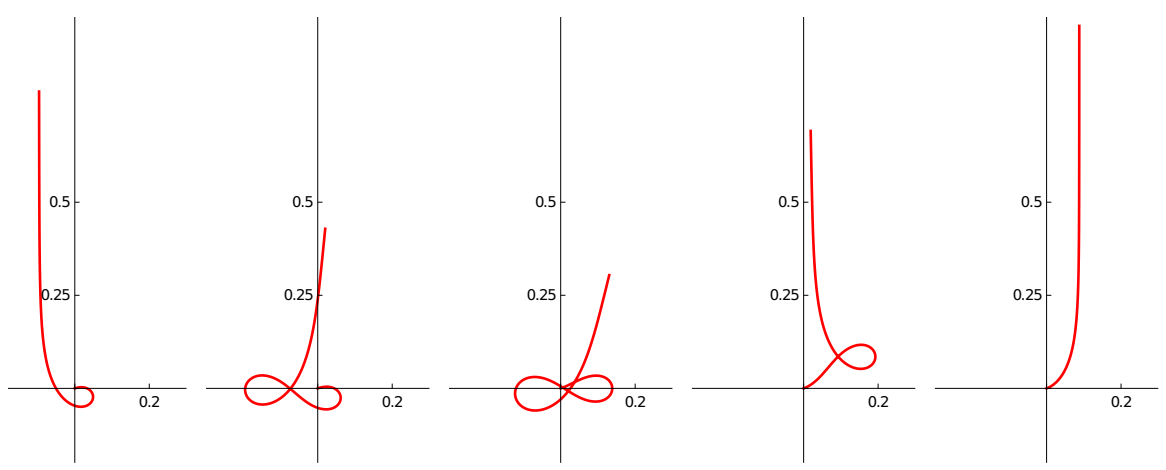

Fig. 2.10 Clamped inextensible Timoshenko beam with a transversal applied load $b=250$ $\left(k_{t}=7000\right)$
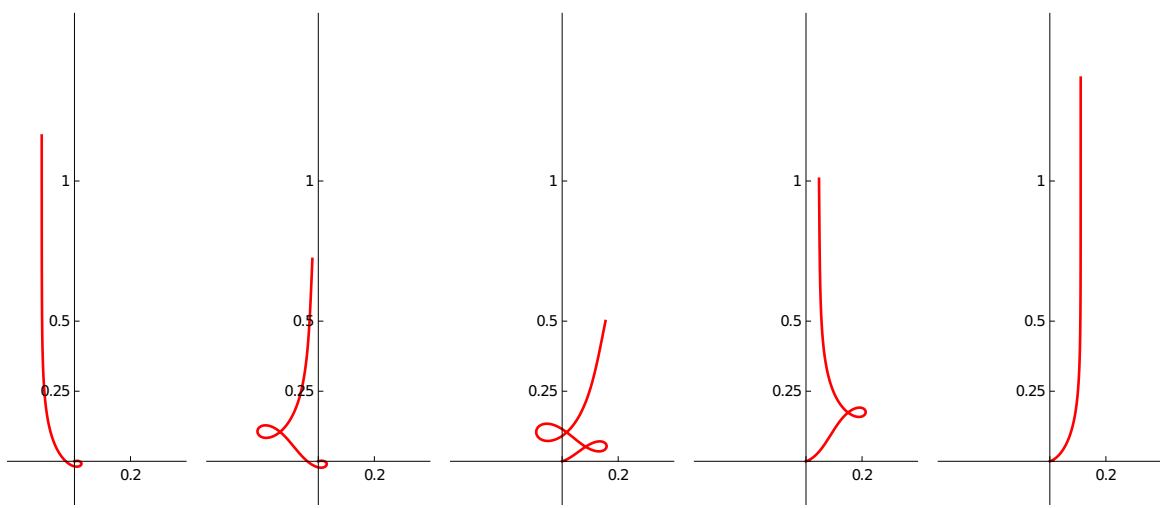

Fig. 2.11 Clamped extensible Timoshenko beam with a transverse applied load $b=250$ $\left(k_{t}=7000, k_{e}=3000\right)$

deformation relative to Figs. 2.10 and 2.11 are shown respectively in Figs. 2.17 and 2.19 .

It is not clear whether the solutions shown herein for the extensible Euler and Timoshenko models can be stable-while in Della Corte et al (2019) it has been proved that for the inextensible Euler case only the left and right configurations of Figs. 2.4 and 2.8 can be stable.

\subsubsection{Parametric Study on the Extensional Stiffness}

When the parameter $k_{e}$ diverges, the beam model tends to inextensibility. The effect of decreasing $k_{e}$ is evaluated for the Euler and Timoshenko models respectively in Figs. 2.24 and 2.26 for $b=120$. In Figs. 2.25 and 2.27 the local elongation $\alpha(s)$ is 

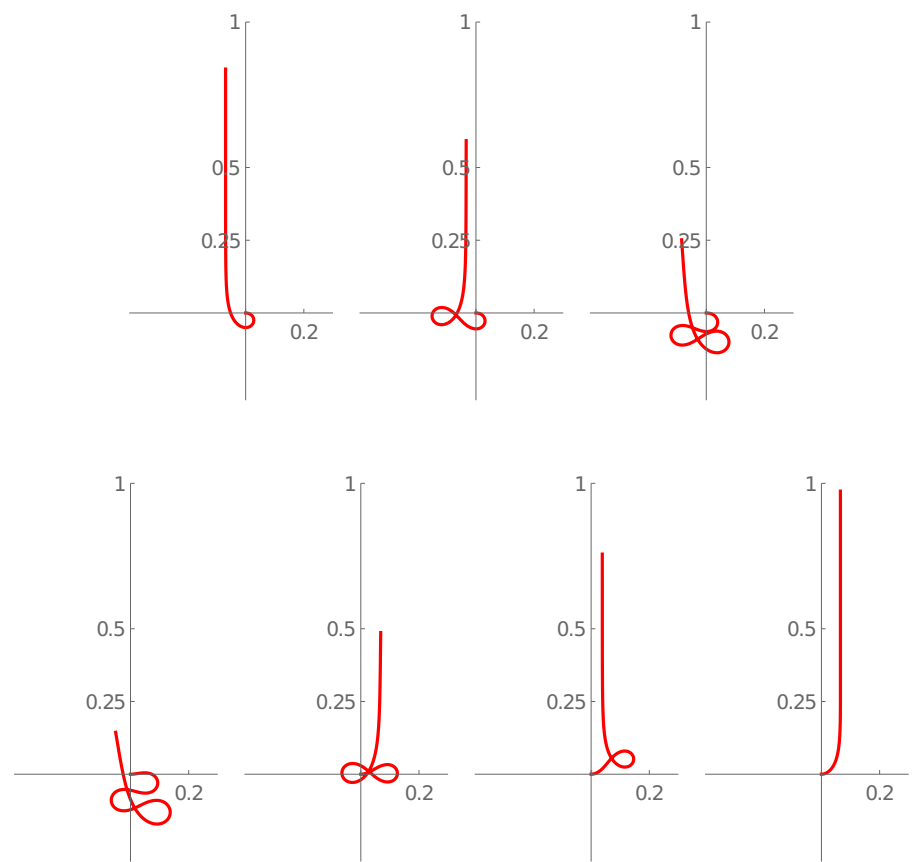

Fig. 2.12 Clamped inextensible Euler beam with a transverse applied load $b=500$.
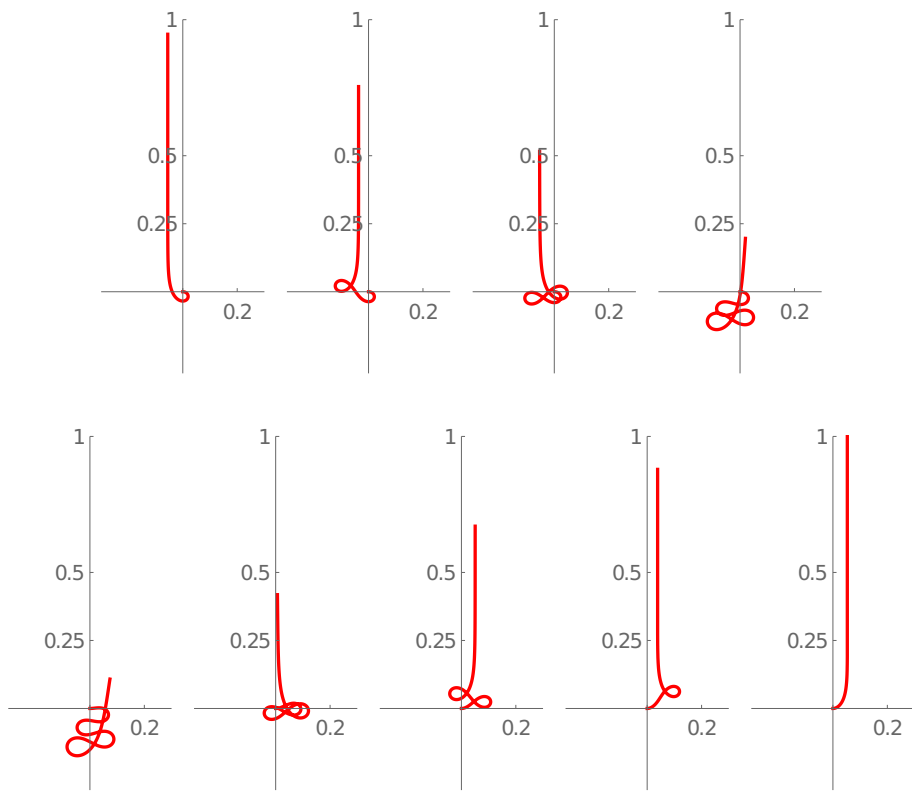

Fig. 2.13 Clamped extensible Euler beam with a transverse applied load $b=500$ and $k_{e}=5000$. 

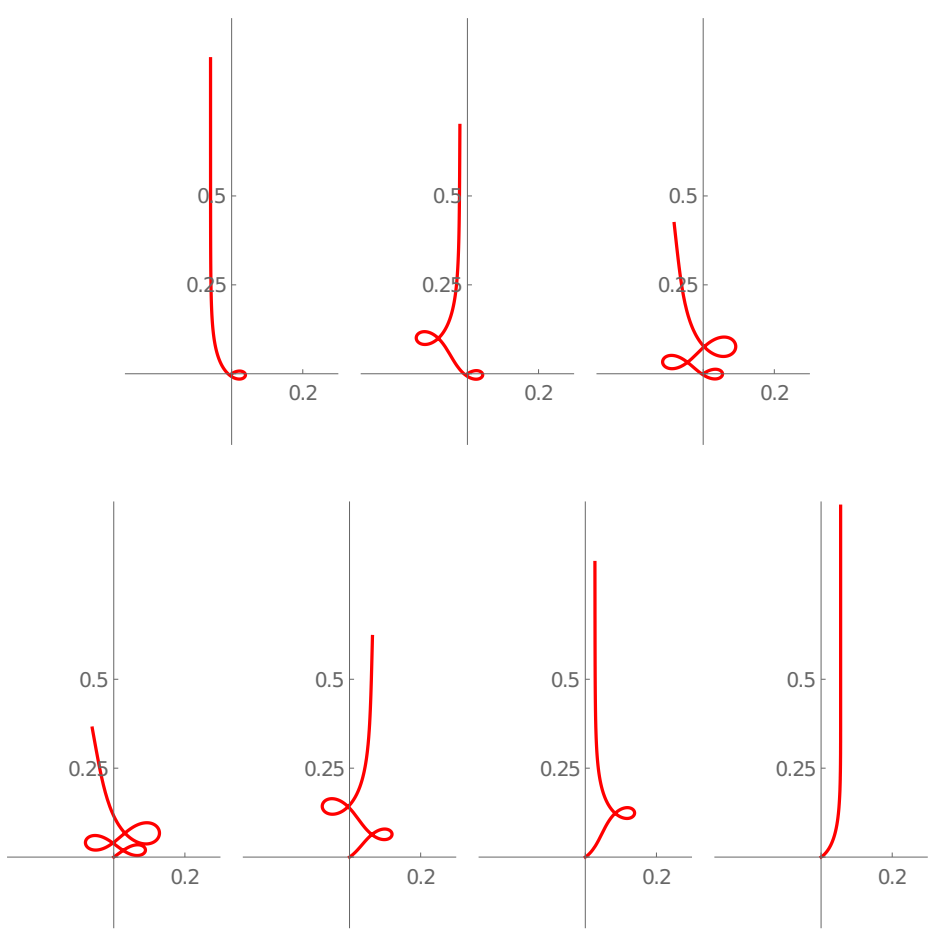

Fig. 2.14 Clamped inextensible Timoshenko beam with a transverse applied load $b=500$ and $k_{t}=7000$.

shown for the two previous cases respectively. The elongation reaches its maximum (minimum) value where the beam lies parallel to the load with the same (opposite) direction. Instead, it is close to 1 where the beam lies orthogonal to the load. While in the Euler case the change in $k_{e}$ causes a minimal change in the deformed shape, in the Timoshenko case there is a much more relevant influence of $k_{e}$ on the configuration. In particular, decreasing $k_{e}$ allows a much larger maximum value of the local geometrical curvature $\gamma:=\theta^{\prime} / \alpha$ of the beam. This maximum is attained when $\theta(s)=-\pi / 2$; we will define $s_{0}$ the point at which this occurs. It has to be noted, however, that the Chebyshev curvature $\theta^{\prime}\left(s_{0}\right)$ takes similar values in the two cases. For instance, in the rightmost simulation of Fig. 2.24 we have $\theta^{\prime}\left(s_{0}\right) \approx-16.4$ and $\gamma\left(s_{0}\right) \approx-17.9$, while in the rightmost simulation of Fig. 2.26 we have $\theta^{\prime}\left(s_{0}\right) \approx-16.3$ and $\gamma\left(s_{0}\right) \approx-111.9$ (we point out that $s_{0} \approx 0.303$ in the right panel of Fig. 2.24 and $s_{0} \approx 0.288$ in the right panel of Fig. 2.26). 


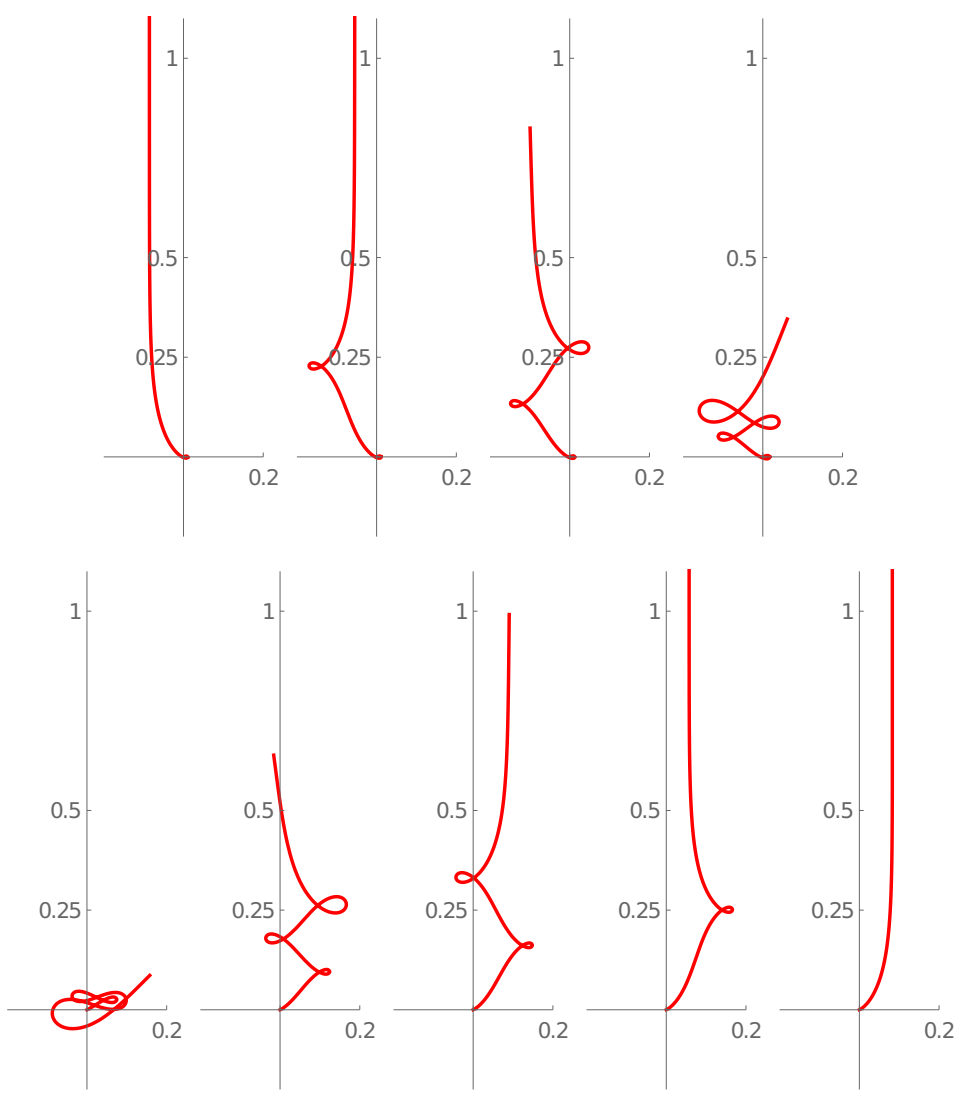

Fig. 2.15 Clamped extensible Timoshenko beam with a transverse applied load $b=500$ and $k_{t}=7000$ and $k_{e}=5000$.
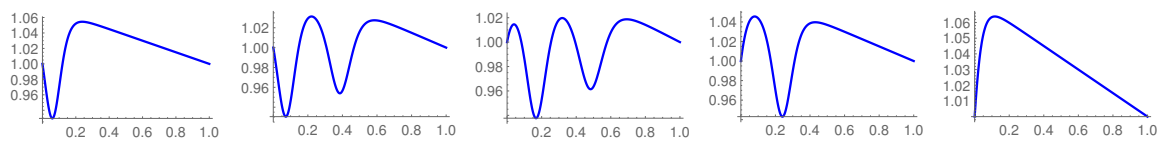

Fig. 2.16 Plot of $\alpha$ for the five configurations in Fig. 2.9.

\subsection{Conclusions}

In this paper we numerically studied clamped-free Euler and Timoshenko beams in large deformation under distributed load. Extensibility has been taken into account and results on the static behavior of the beam under different values of the load and of the axial stiffness has been shown. The main interest of the results consists in the multiplicity of solutions that arise as the load increases, not as a bifurcation of ex- 

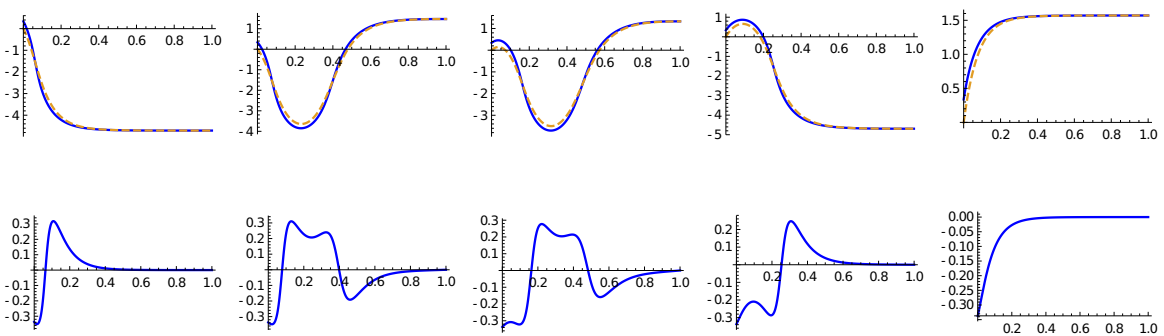

Fig. 2.17 Above: plot of $\phi$ (dotted) and $\theta$ for the five configurations shown in Fig. 2.10. Below: the corresponding plot of $\phi-\theta$.
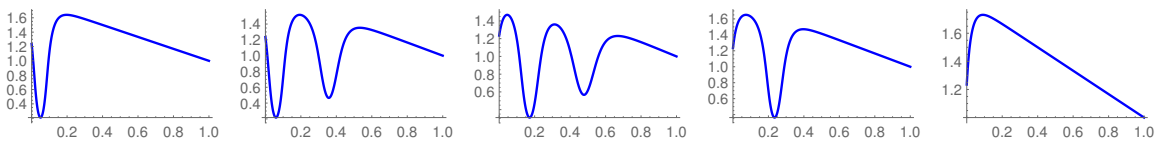

Fig. 2.18 Plot of $\alpha$ for the five configurations in Fig. 2.11.
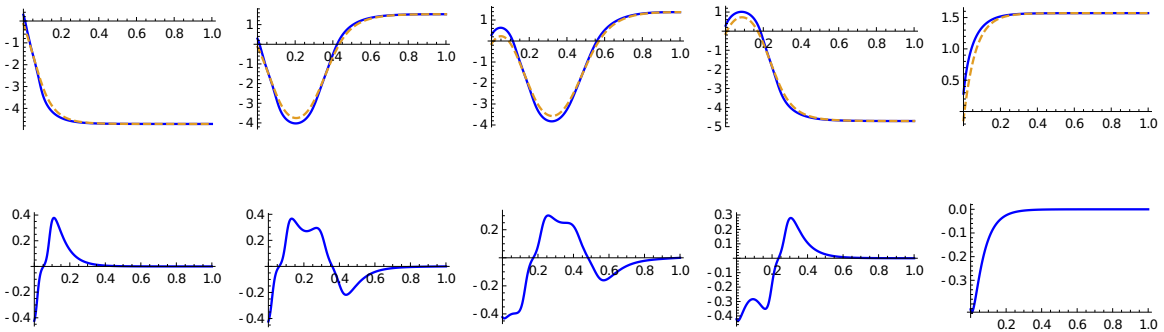

Fig. 2.19 Above: plot of $\phi$ (dotted) and $\theta$ for the five configurations shown in Fig. 2.11. Below: the corresponding plot of $\phi-\theta$.
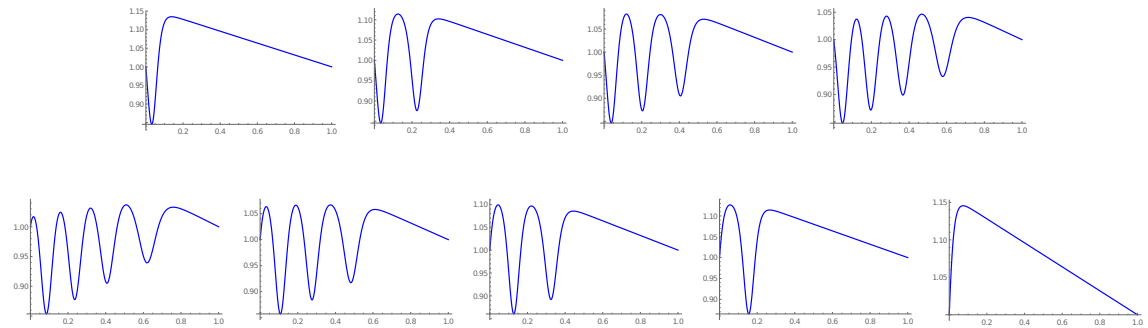

Fig. 2.20 Plot of $\alpha$ for the configurations in Fig. 2.13.

isting branches of solutions but as new branches that arise when the load overcomes a series of progressively larger threshold-values. Future investigations are required to establish whether these multiple solutions can be stable. In this regard, an analysis of the small oscillations of the beam around candidate stable equilibria would be useful to assess numerically the question. Moreover, addressing theoretically the 

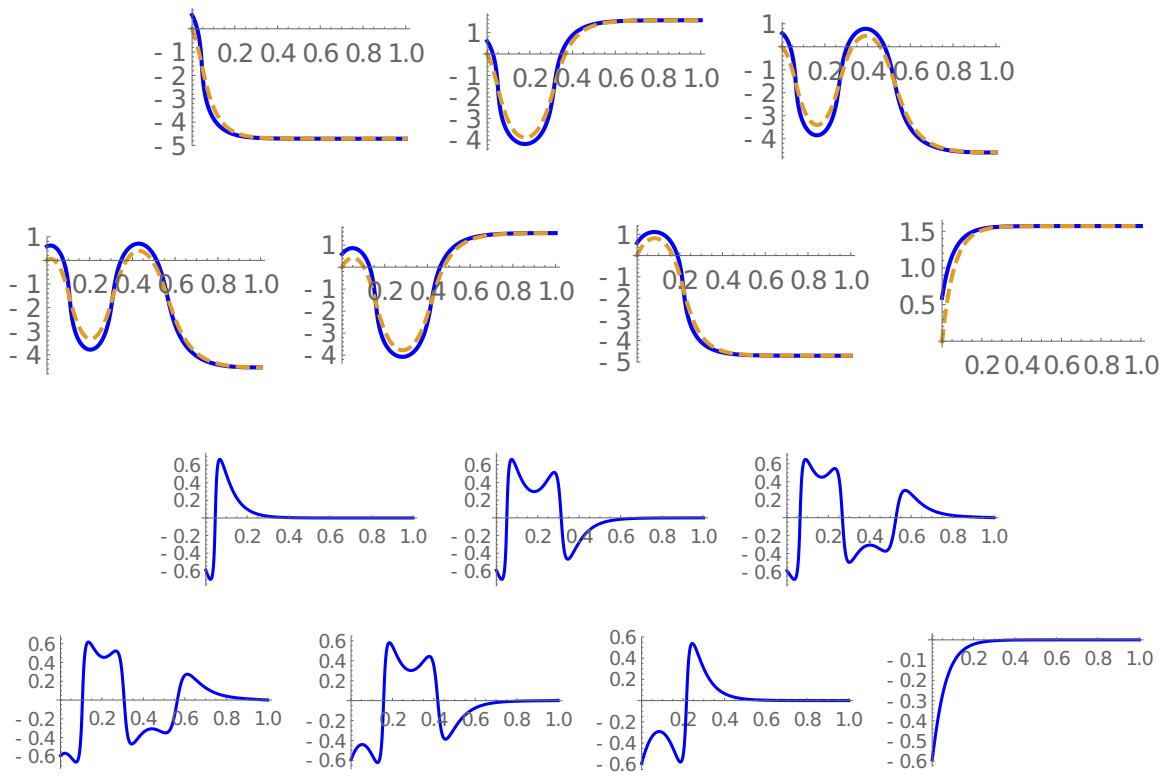

Fig. 2.21 Above: plot of $\phi$ (dotted) and $\theta$ for the five configurations shown in Fig. 2.14. Below: the corresponding plot of $\phi-\theta$.
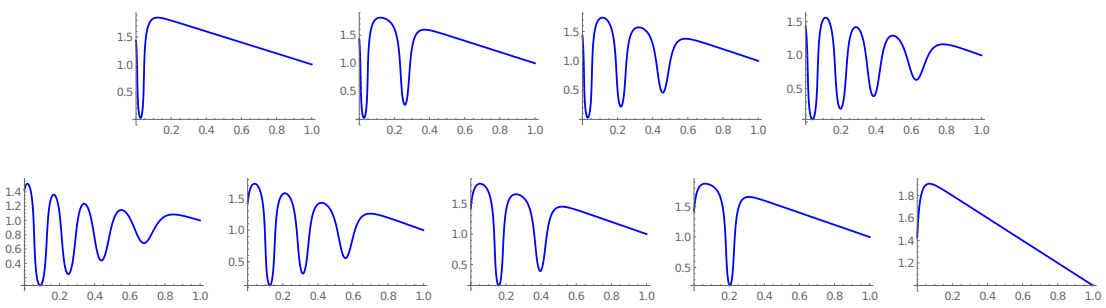

Fig. 2.22 Plot of $\alpha$ for the configurations in Fig. 2.15.

dynamical behavior of the nonlinear version of the Timoshenko beam model proposed here is a challenging task. The results developed in Berezovski et al (2018); Luongo and D'Annibale (2013); Piccardo et al (2015b); Taig et al (2015); Piccardo et al (2015a); Chróścielewski et al (2019) may prove useful in this direction.

Apart from the models introduced here, an independent and novel approach to understand the large deformation of beams to be investigated in the future is to regard a beam as the boundary curve of a two-dimensional manifold in a threedimensional space. In doing so, not only is the curve endowed with its own energy similar to that in the context of lower-dimensional energetics (Javili et al, 2013b) but also in a geometrically nonlinear framework (Javili et al, 2014) and in accordance with higher gradient elasticity accounting for boundary energetics elaborated in Javili et al (2013a). The advantage of this approach, particularly from a computational 

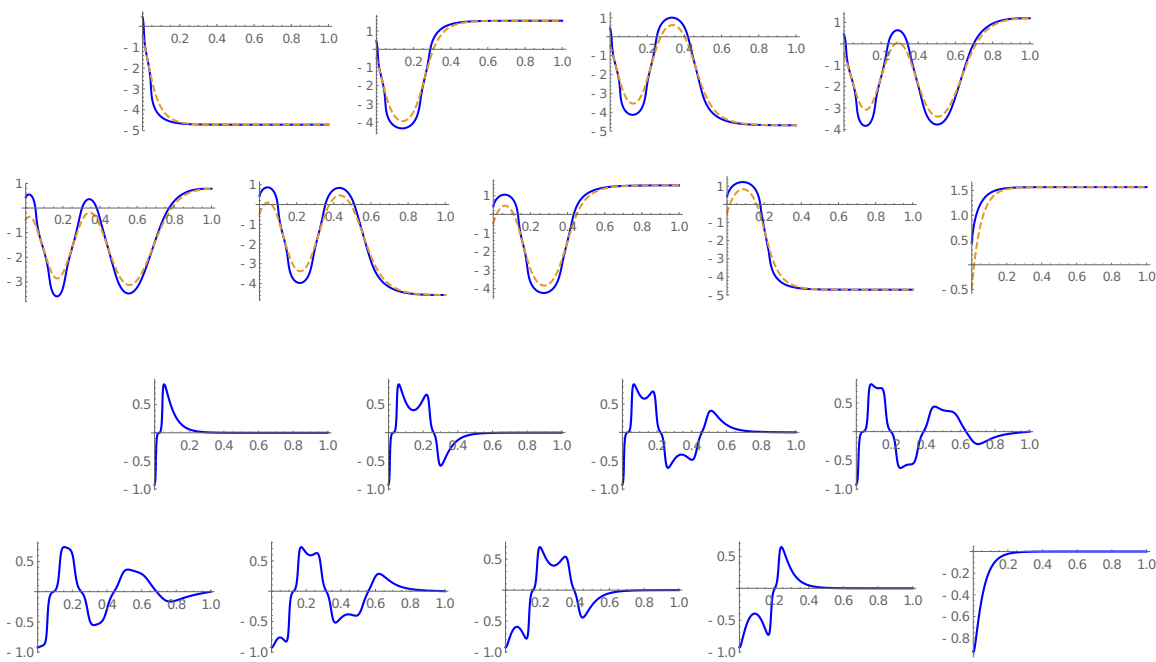

Fig. 2.23 Above: plot of $\phi$ (dotted) and $\theta$ for the five configurations shown in Fig. 2.15. Below: the corresponding plot of $\phi-\theta$.
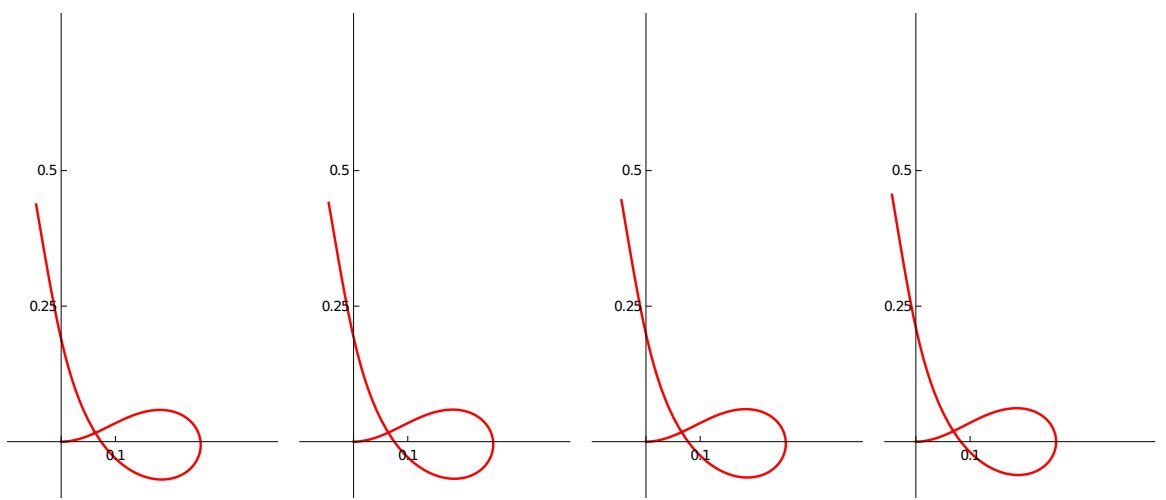

Fig. 2.24 Parametric study on a clamped extensible Euler beam with a transversal applied load $b=120$ with $k_{e}=2500, k_{e}=2000, k_{e}=1500, k_{e}=1000$.
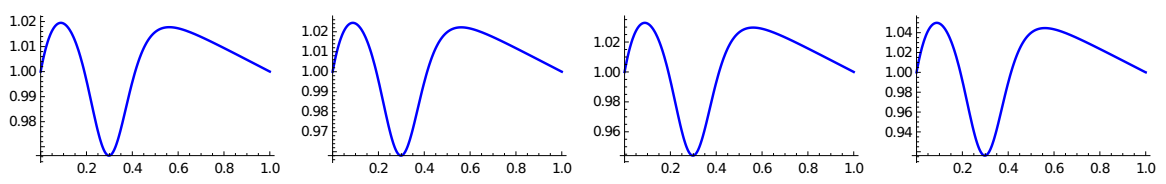

Fig. 2.25 The local elongation $\alpha(s)$ relative to the equilibrium shapes shown in Fig. 2.24. 

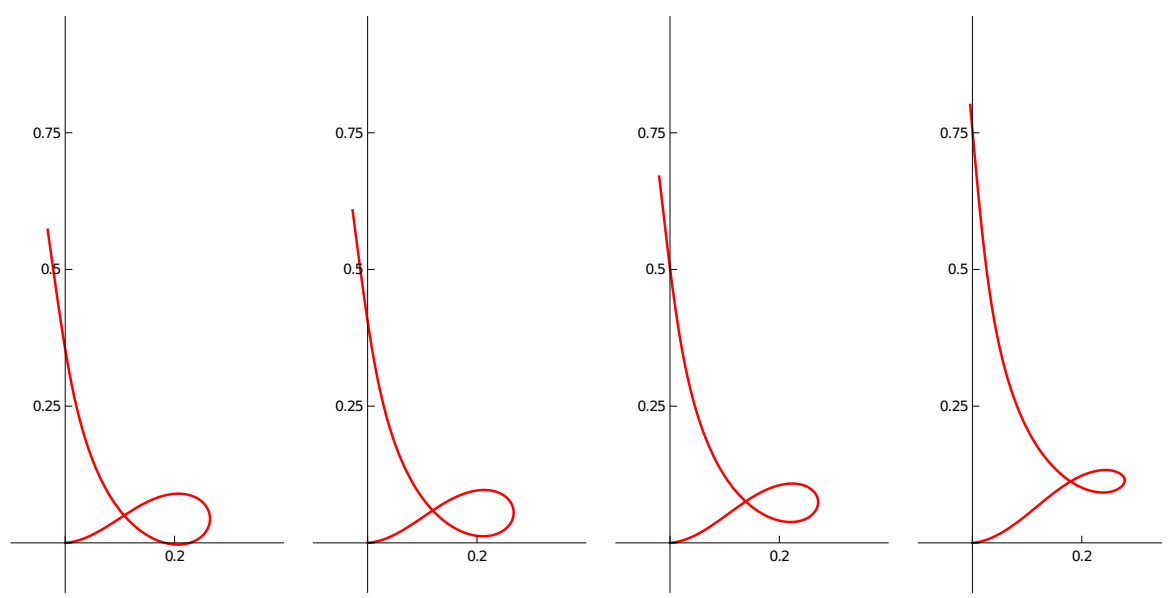

Fig. 2.26 Parametric study on a clamped extensible Timoshenko beam with a transversal applied load $b=120$ with $k_{e}=2500, k_{e}=2000, k_{e}=1500, k_{e}=1000\left(k_{t}=18000\right)$.
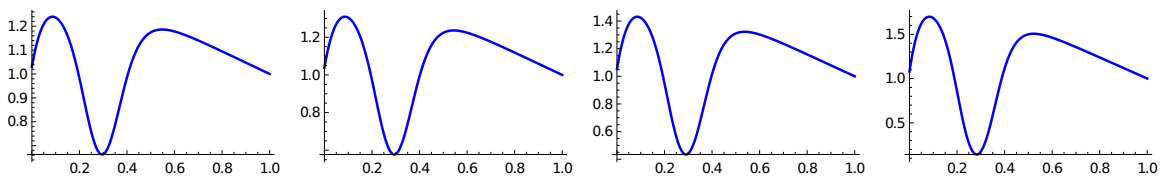

Fig. 2.27 The local elongation $\alpha(s)$ relative to the equilibrium shapes shown in Fig. 2.26.

viewpoint, is that the bulk material acts to regularize the behavior of the beam especially important to analyze the instabilities associated with thin beams similar to the instabilities of thin films on an elastic foundation (Javili et al, 2015). Obviously, in the limiting case of the vanishing bulk one would recover exactly the beam theory.

\section{Appendix}

We show here the Euler-Lagrange boundary value problem associated with the functional (2.5). We recall that the solutions $\theta(s)$ of this BVP are the scalar fields of angles formed by the tangent to the deformed configuration and a reference axis at the equilibrium for a clamped-free, extensible Timoshenko beam, in large deformation regime, under distributed load. 


$$
\begin{aligned}
\theta^{\prime \prime}= & {\left[k_{b}\left(b k_{e}(1-s) \sin (\theta)-(b(1-s))^{2}(\cos (2 \theta))+k_{e} k_{t}\right)\right]^{-1} } \\
& {\left[b k_{b}(1-s) \theta^{2} \cos (\theta)\left(4 b(1-s) \sin (\theta)+k_{e}\right)-2 b k_{b} \theta(2 b(1-s) \cos (2 \theta)+\right.} \\
& \left.\left.-k_{e} \sin (\theta)\right)+\cos (\theta)\left(2 b^{2} k_{b} \sin (\theta)-b k_{t}(1-s)\left(b(1-s) \sin (\theta)+k_{e}\right)\right)\right]
\end{aligned}
$$

with boundary conditions:

$$
\begin{aligned}
& \left.\left(\theta-\frac{b^{2}(1-s)^{2} \sin (\theta) \cos (\theta)}{k_{e} k_{e}}+\frac{b(1-s) \cos (\theta)}{k_{e}}\right)\right|_{s=0}=0 \\
& \left.\left(\theta-\frac{b^{2}(1-s)^{2} \sin (\theta) \cos (\theta)}{k_{e} k_{e}}+\frac{b(1-s) \cos (\theta)}{k_{e}}\right)^{\prime}\right|_{s=1}=0
\end{aligned}
$$

Remark 2.2. The boundary conditions in the previous problem have in general more than one solution. In the numerical simulations, we always considered the value $\theta(0)$ which was smaller in absolute value.

\section{References}

Altenbach H, Eremeyev VA (2013) Cosserat-type shells. In: Altenbach H, Eremeyev VA (eds) Generalized Continua from the Theory to Engineering Applications, CISM International Centre for Mechanical Sciences, vol 541, Springer, Vienna, pp 131-178

Altenbach H, Birsan M, Eremeyev VA (2013) Cosserat-type rods. In: Altenbach H, Eremeyev VA (eds) Generalized Continua from the Theory to Engineering Applications, CISM International Centre for Mechanical Sciences, vol 541, Springer, Vienna, pp 179-248

Altenbach J, Altenbach H, Eremeyev VA (2010) On generalized Cosserat-type theories of plates and shells: a short review and bibliography. Archive of Applied Mechanics 80(1):73-92

Andreaus U, Spagnuolo M, Lekszycki T, Eugster SR (2018) A Ritz approach for the static analysis of planar pantographic structures modeled with nonlinear Euler-Bernoulli beams. Continuum Mechanics and Thermodynamics 30(5):1103-1123

Antman SS, Renardy M (1995) Nonlinear problems of elasticity. SIAM Review 37(4):637

Atai AA, Steigmann DJ (1997) On the nonlinear mechanics of discrete networks. Archive of Applied Mechanics 67(5):303-319

Ball JM, Mizel VJ (1987) One-dimensional variational problems whose minimizers do not satisfy the Euler-Lagrange equation. In: Analysis and Thermomechanics, Springer, pp 285-348

Balobanov V, Niiranen J (2018) Locking-free variational formulations and isogeometric analysis for the timoshenko beam models of strain gradient and classical elasticity. Computer Methods in Applied Mechanics and Engineering 339:137-159

Barchiesi E, dell'Isola F, Laudato M, Placidi L, Seppecher P (2018) A 1D continuum model for beams with pantographic microstructure: Asymptotic micro-macro identification and numerical results. In: dell'Isola F, Eremeyev V, Porubov A (eds) Advances in Mechanics of Microstructured Media and Structures, Advanced Structured Materials, vol 87, Springer, Cham, pp 43-74

Barchiesi E, Spagnuolo M, Placidi L (2019) Mechanical metamaterials: a state of the art. Mathematics and Mechanics of Solids 24(1):212-234

Battista A, Della Corte A, dell'Isola F, Seppecher P (2018) Large deformations of 1D microstructured systems modeled as generalized Timoshenko beams. Zeitschrift für angewandte Mathematik und Physik 69(3):52 
Berezovski A, Yildizdag M, Scerrato D (2018) On the wave dispersion in microstructured solids. Continuum Mechanics and Thermodynamics pp 1-20, DOI 10.1007/s00161-018-0683-1

Bernoulli D (1843) The 26th letter to Euler. Correspondence Mathématique et Physique 2

Bernoulli J (1691) Quadratura curvae, e cujus evolutione describitur inflexae laminae curvatura. Die Werke von Jakob Bernoulli pp 223-227

Birsan M, Altenbach H, Sadowski T, Eremeyev V, Pietras D (2012) Deformation analysis of functionally graded beams by the direct approach. Composites Part B: Engineering 43(3):13151328

Boubaker BB, Haussy B, Ganghoffer J (2007) Discrete models of woven structures. macroscopic approach. Composites Part B: Engineering 38(4):498-505

Boutin C, Giorgio I, Placidi L, et al (2017) Linear pantographic sheets: Asymptotic micro-macro models identification. Mathematics and Mechanics of Complex Systems 5(2):127-162

Cazzani A, Malagù M, Turco E (2016) Isogeometric analysis of plane-curved beams. Mathematics and Mechanics of Solids 21(5):562-577

Challamel N (2013) Variational formulation of gradient or/and nonlocal higher-order shear elasticity beams. Composite Structures 105:351-368

Challamel N, Zhang Z, Wang C (2013) Nonlocal equivalent continua for buckling and vibration analyses of microstructured beams. Journal of Nanomechanics and Micromechanics 5(1):A4014,004

Chebyshev P (1878) Sur la coupe des vetements. Complete works by PL Chebyshev 5:165-170

Chróścielewski J, Schmidt R, Eremeyev VA (2019) Nonlinear finite element modeling of vibration control of plane rod-type structural members with integrated piezoelectric patches. Continuum Mechanics and Thermodynamics 31(1):147-188

Cosserat E, Cosserat F (1909) Théorie des corps déformables. A Hermann et fils

Della Corte A, dell' Isola F, Esposito R, Pulvirenti M (2016) Equilibria of a clamped Euler beam (Elastica) with distributed load: Large deformations. Mathematical Models and Methods in Applied Sciences pp 1-31

Della Corte A, Battista A, dell'Isola F, Seppecher P (2019) Large deformations of Timoshenko and Euler beams under distributed load. Zeitschrift für angewandte Mathematik und Physik 70(52), DOI 10.1007/s00033-019-1098-y

dell'Isola F, Giorgio I, Pawlikowski M, Rizzi N (2016a) Large deformations of planar extensible beams and pantographic lattices: heuristic homogenization, experimental and numerical examples of equilibrium. Proceedings of the Royal Society A: Mathematical, Physical and Engineering Sciences 472(2185):20150,790

dell'Isola F, Steigmann D, Della Corte A (2016b) Synthesis of fibrous complex structures: designing microstructure to deliver targeted macroscale response. Applied Mechanics Reviews 67(6):060,804-060,804-21

dell'Isola F, Seppecher P, Alibert JJ, Lekszycki T, Grygoruk R, Pawlikowski M, Steigmann D, Giorgio I, Andreaus U, Turco E, Golaszewski M, Rizzi N, Boutin C, Eremeyev VA, Misra A, Placidi L, Barchiesi E, Greco L, Cuomo M, Cazzani A, Corte AD, Battista A, Scerrato D, Eremeeva IZ, Rahali Y, Ganghoffer JF, Müller W, Ganzosch G, Spagnuolo M, Pfaff A, Barcz K, Hoschke K, Neggers J, Hild F (2018) Pantographic metamaterials: an example of mathematically driven design and of its technological challenges. Continuum Mechanics and Thermodynamics 31(4):851-884

Diyaroglu C, Oterkus E, Oterkus S, Madenci E (2015) Peridynamics for bending of beams and plates with transverse shear deformation. International Journal of Solids and Structures 69:152168

Diyaroglu C, Oterkus E, Oterkus S (2017) An Euler-Bernoulli beam formulation in an ordinary state-based peridynamic framework. Mathematics and Mechanics of Solids 24(2):361-376

Dortdivanlioglu B, Javili A, Linder C (2017) Computational aspects of morphological instabilities using isogeometric analysis. Computer Methods in Applied Mechanics and Engineering 316:261-279

Dos Reis F, Ganghoffer J (2012) Construction of micropolar continua from the asymptotic homogenization of beam lattices. Computers \& Structures 112:354-363 
Engelbrecht J, Berezovski A (2015) Reflections on mathematical models of deformation waves in elastic microstructured solids. Mathematics and Mechanics of Complex Systems 3(1):43-82

Engelbrecht J, Berezovski A, Pastrone F, Braun M (2005) Waves in microstructured materials and dispersion. Philosophical Magazine 85(33-35):4127-4141

Eremeyev VA (2017) On characterization of an elastic network within the six-parameter shell theory. In: Pietraszkiewicz W, Witkowski W (eds) Shell Structures: Theory and Applications Volume 4: Proceedings of the 11th International Conference in Shell Structures: Theory and Applications, SSTA 2017, CRC Press, pp 81-84

Eremeyev VA, Pietraszkiewicz W (2016) Material symmetry group and constitutive equations of micropolar anisotropic elastic solids. Mathematics and Mechanics of Solids 21(2):210-221

Eugster S, Hesch C, Betsch P, Glocker C (2014) Director-based beam finite elements relying on the geometrically exact beam theory formulated in skew coordinates. International Journal for Numerical Methods in Engineering 97(2):111-129

Eugster SR (2015) Geometric Continuum Mechanics and Induced Beam Theories, Lecture Notes in Applied and Computational Mechanics, vol 75. Springer

Euler L (1952) Methodus inveniendi lineas curvas maximi minimive proprietate gaudentes sive solutio problematis isoperimetrici latissimo sensu accepti (ed. by C. Carathéodory), Opera mathematica, vol 1. Birkhäuser, Basel

Fertis DG (2006) Nonlinear Structural Engineering. Springer

Forest S (2005) Mechanics of Cosserat media - an introduction. Ecole des Mines de Paris, Paris pp $1-20$

Franciosi P, Spagnuolo M, Salman OU (2019) Mean Green operators of deformable fiber networks embedded in a compliant matrix and property estimates. Continuum Mechanics and Thermodynamics 31(1):101-132

Giorgio I, Del Vescovo D (2018) Non-linear lumped-parameter modeling of planar multi-link manipulators with highly flexible arms. Robotics 7(4):60

Giorgio I, Rizzi N, Turco E (2017) Continuum modelling of pantographic sheets for out-of-plane bifurcation and vibrational analysis. Proceedings of the Royal Society A: Mathematical, Physical and Engineering Sciences 473(2207):20170,636

Golaszewski M, Grygoruk R, Giorgio I, Laudato M, Di Cosmo F (2019) Metamaterials with relative displacements in their microstructure: technological challenges in 3D printing, experiments and numerical predictions. Continuum Mechanics and Thermodynamics 31(4):1015-1034

Greco L, Cuomo M, Contrafatto L, Gazzo S (2017) An efficient blended mixed b-spline formulation for removing membrane locking in plane curved Kirchhoff rods. Computer Methods in Applied Mechanics and Engineering 324:476-511

Guckenheimer J, Holmes P (1983) Nonlinear Oscillations, Dynamical Systems, and Bifurcations of Vector Fields, Applied Mathematical Sciences, vol 42. Springer

Javili A, dell'Isola F, Steinmann P (2013a) Geometrically nonlinear higher-gradient elasticity with energetic boundaries. Journal of the Mechanics and Physics of Solids 61(12):2381-2401

Javili A, McBride A, Steinmann P (2013b) Thermomechanics of solids with lower-dimensional energetics: on the importance of surface, interface, and curve structures at the nanoscale. a unifying review. Applied Mechanics Reviews 65(1):010,802

Javili A, McBride A, Steinmann P, Reddy B (2014) A unified computational framework for bulk and surface elasticity theory: a curvilinear-coordinate-based finite element methodology. Computational Mechanics 54(3):745-762

Javili A, Dortdivanlioglu B, Kuhl E, Linder C (2015) Computational aspects of growth-induced instabilities through eigenvalue analysis. Computational Mechanics 56(3):405-420

Jawed MK, Novelia A, O'Reilly OM (2018) A Primer on the Kinematics of Discrete Elastic Rods. Springer

Ladevèze P (2012) Nonlinear Computational Structural Mechanics: New Approaches and Nonincremental Methods of Calculation. Springer Science \& Business Media

Luongo A, D’Annibale F (2013) Double zero bifurcation of non-linear viscoelastic beams under conservative and non-conservative loads. International Journal of Non-Linear Mechanics $55: 128-139$ 
Luongo A, Zulli D (2013) Mathematical Models of Beams and Cables. John Wiley \& Sons

Milton G, Briane M, Harutyunyan D (2017) On the possible effective elasticity tensors of 2dimensional and 3-dimensional printed materials. Mathematics and Mechanics of Complex Systems 5(1):41-94

Misra A, Placidi L, Scerrato D (2016) A review of presentations and discussions of the workshop computational mechanics of generalized continua and applications to materials with microstructure that was held in Catania 29-31 October 2015. Mathematics and Mechanics of Solids 22(9):1891-1904

Misra A, Lekszycki T, Giorgio I, Ganzosch G, Müller WH, dell' Isola F (2018) Pantographic metamaterials show atypical poynting effect reversal. Mechanics Research Communications 89:610

Niiranen J, Balobanov V, Kiendl J, Hosseini S (2017) Variational formulations, model comparisons and numerical methods for Euler-Bernoulli micro-and nano-beam models. Mathematics and Mechanics of Solids 24(1):312-335

Pepe G, Carcaterra A, Giorgio I, Del Vescovo D (2016) Variational feedback control for a nonlinear beam under an earthquake excitation. Mathematics and Mechanics of Solids 21(10):1234-1246

Piccardo G, Pagnini LC, Tubino F (2015a) Some research perspectives in galloping phenomena: critical conditions and post-critical behavior. Continuum Mechanics and Thermodynamics 27(1-2):261-285

Piccardo G, Tubino F, Luongo A (2015b) A shear-shear torsional beam model for nonlinear aeroelastic analysis of tower buildings. Zeitschrift für angewandte Mathematik und Physik 66(4):1895-1913

Placidi L, Rosi G, Giorgio I, Madeo A (2014) Reflection and transmission of plane waves at surfaces carrying material properties and embedded in second-gradient materials. Mathematics and Mechanics of Solids 19(5):555-578

Placidi L, Greco L, Bucci S, Turco E, Rizzi NL (2016) A second gradient formulation for a 2D fabric sheet with inextensible fibres. Zeitschrift für angewandte Mathematik und Physik 67(5):114

Placidi L, Andreaus U, Giorgio I (2017) Identification of two-dimensional pantographic structure via a linear d4 orthotropic second gradient elastic model. Journal of Engineering Mathematics 103(1):1-21

Ravari MRK, Kadkhodaei M (2015) A computationally efficient modeling approach for predicting mechanical behavior of cellular lattice structures. Journal of Materials Engineering and Performance 24(1):245-252

Ravari MRK, Kadkhodaei M, Badrossamay M, Rezaei R (2014) Numerical investigation on mechanical properties of cellular lattice structures fabricated by fused deposition modeling. International Journal of Mechanical Sciences 88:154-161

Ravari MRK, Kadkhodaei M, Ghaei A (2016) Effects of asymmetric material response on the mechanical behavior of porous shape memory alloys. Journal of Intelligent Material Systems and Structures 27(12):1687-1701

Reda H, Rahali Y, Ganghoffer JF, Lakiss H (2016) Wave propagation in 3D viscoelastic auxetic and textile materials by homogenized continuum micropolar models. Composite Structures 141:328-345

Rezaei DAH, Kadkhodaei M, Nahvi H (2012) Analysis of nonlinear free vibration and damping of a clamped-clamped beam with embedded prestrained shape memory alloy wires. Journal of Intelligent Material Systems and Structures 23(10):1107-1117

Romano G, Rosati L, Ferro G (1992) Shear deformability of thin-walled beams with arbitrary cross sections. International Journal for Numerical Methods in Engineering 35(2):283-306

Scerrato D, Giorgio I, Rizzi NL (2016) Three-dimensional instabilities of pantographic sheets with parabolic lattices: numerical investigations. Zeitschrift für angewandte Mathematik und Physik 67(3):53

Serpieri R, Rosati L (2014) A frame-independent solution to Saint-Venant's flexure problem. Journal of Elasticity 116(2):161-187 
Spagnuolo M, Barcz K, Pfaff A, dell'Isola F, Franciosi P (2017) Qualitative pivot damage analysis in aluminum printed pantographic sheets: numerics and experiments. Mechanics Research Communications 83:47-52

Steigmann D, Faulkner M (1993) Variational theory for spatial rods. Journal of Elasticity 33(1):126

Steigmann DJ (2017) Finite Elasticity Theory. Oxford University Press

Taig G, Ranzi G, D'annibale F (2015) An unconstrained dynamic approach for the generalised beam theory. Continuum Mechanics and Thermodynamics 27(4-5):879-904

Timoshenko SP (1921) Lxvi. on the correction for shear of the differential equation for transverse vibrations of prismatic bars. The London, Edinburgh, and Dublin Philosophical Magazine and Journal of Science 41(245):744-746

Timoshenko SP (1922) X. on the transverse vibrations of bars of uniform cross-section. The London, Edinburgh, and Dublin Philosophical Magazine and Journal of Science 43(253):125-131

Turco E (2018) Discrete is it enough? the revival of Piola-Hencky keynotes to analyze threedimensional Elastica. Continuum Mechanics and Thermodynamics 30(5):1039-1057

Turco E, Golaszewski M, Cazzani A, Rizzi NL (2016) Large deformations induced in planar pantographic sheets by loads applied on fibers: experimental validation of a discrete lagrangian model. Mechanics Research Communications 76:51-56

Turco E, Golaszewski M, Giorgio I, D’Annibale F (2017) Pantographic lattices with nonorthogonal fibres: Experiments and their numerical simulations. Composites Part B: Engineering 118:1-14

Turco E, Misra A, Sarikaya R, Lekszycki T (2019) Quantitative analysis of deformation mechanisms in pantographic substructures: experiments and modeling. Continuum Mechanics and Thermodynamics 31(1):209-223 